\title{
Modelling and measuring price discovery in commodity markets
}

\author{
Isabel Figuerola-Ferretti ${ }^{\mathrm{a}}$, Jesús Gonzalo ${ }^{\mathrm{b}, *}$ \\ a Business Department, Universidad Carlos ID de Madrid, Spain \\ b Economio Department, Universidad Carlos UI de Madrid, Spain
}

IEL classification:
C32
C51
G13
G14
Keywords:
Backwardation
Cointegration
Commodity markets
Contango
Convenience yield
Futures prices
Permanent-Transitory decomposition
Price discovery

\section{Introduction}

Futures markets contribute in two important ways to the organization of economic activity: (i) they facilitate price discovery: and (ii) they offer a means of transferring risk or hedging. In this paper we focus on the first contribution. Price discovery refers to the use of futures prices for pricing cash market transactions (Working 1948; Wiese, 1978; Lake, 1978). In general, price discovery is the process of uncovering an asset's full information or permanent value. The unobservable permanent price reflects the fundamental value of the stock or commodity. It is distinct from the observable price, which can be decomposed into its fundamental value and transitory effects. The latter consists of price movements due to factors such as bid-ask bounce, temporary order imbalances or inventory adjustments.

Whether the spot or the futures market is the center of price discovery in commodity markets has for a long time been discussed in the literature. Stein (1961) showed that futures and

\footnotetext{
* Comesponding author.

E-mail address: jesus.gonzaloeve3mes (J. Gonzalo).
}

spot prices for a given commodity are determined simultaneously. Garbade and Silber (1983) (GS thereafter) develop a model of simultaneous price dynamics in which they establish that price discovery takes place in the market with the highest number of participants. Their empirical application concludes that "about 75\% of new information is incorporated first in the futures prices." More recently, the price discovery research has focused on microstructure models and on methods to measure it This line of literature applies two methodologies (see Lehman, 2002; special issue in the Journal of Financial Markets), the Information Shares of Hasbrouck (1995) (IS thereafter) and the Gonzalo and Granger (1995) Permanent-Transitory decomposition (PT thereafter). Our paper suggests a practical econometric approach to characterize and measure the phenomenon of price discovery by demonstrating the existence of a perfect link between an extended GS theoretical model and the PT decomposition.

Building on GS, we develop an equilibrium model of commodity spot and futures prices where the elasticity of arbitrage services, contrary to the standard assumption of being infinite, is considered to be finite, and the existence of convenience yields is endogenously modeled as a linear combination of $s_{t}$ and $f_{t}$ satisfying the 
standard no-arbitrage condition. The assumption of finite elasticity is more realistic since it reflects the existence of factors such as basis risks, storage costs, convenience yields, etc. Convenience yields are natural for goods, like art or land, that offer exogenous rental or service flows over time. It is observed in commodities, such as agricultural products, industrial metals and energy, which are consumed at a single point in time. Convenience yields and subsequent price backwardations have attracted considerable attention in the literature (see Routledge et aL., 2000). Backwardation (contango) exists when prices decline (increase) with time-to-delivery, so that spot prices are greater (lower) than futures prices. By explicitly incorporating and modelling convenience yields, we are able to detect the existence of backwardation and contango in the long-run equilibrium relationship between spot and futures prices. In our model, this is reflected on a cointegrating vector, $\left(1,-\boldsymbol{\beta}_{2}\right)$, different from the standard $\beta_{2}=1$. When $\beta_{2}>1(<1)$ the market is under long run backwardation (contango). As a by-product of this modeling we find a theoretical justification for a cointegrating vector between log-variables different from the standard $(1,-1)$. To the best of our knowledge, this is the first time this has been formally considered in this literature. ${ }^{1}$

Independent of the value of $\beta_{2}$, this paper shows that the proposed equilibrium model not only implies cointegration; but it leads into an economically meaningful Error Correction Representation (see Engle and Granger, 1987). The weights defining the linear combination of $s_{t}$ and $f_{t}$ that constitute the common permanent component in the PT decomposition, coincide exactly with the price discovery parameters proposed by GS. These weights depend on the elasticity of arbitrage services and are determined by the liquidity traded in the spot and in the futures market This result not only offers a theoretical justification for the PT decomposition; but it provides a simple way of detecting which of the two prices is long run dominant in the price discovery process. Information on price discovery is important because spot and futures markets are widely used by firms engaged in the production, marketing and processing of commodities. Consumption and production decisions depend on the price signals from these markets.

All the results produced in the paper can easily be tested, as may be seen directly from our application to London Metal Exchange (LME) data. We are interested in these metal markets because they have highly developed futures contracts. Applying our model to LME spot and futures data we find: (i) All markets with the exception of copper are backwarded in equilibrium. This is reflected in a cointegrated slope greater than one, and (ii) The futures price is information dominant for all metals with a liquid futures markets: Aluminium (Al), Copper (Cu), Nickel (Ni) and Zinc $(\mathrm{Zn})$. The spot price is information dominant for Lead $(\mathrm{Pb})$, the least liquid LME contract

The paper is organized as follows. Section 2 describes the equilibrium model with finite elasticity of supply of arbitrage services incorporating endogenously convenience yields. It demonstrates that the model admits an economically meaningful Error Correction Representation, and derives the contribution of the spot and futures prices to the price discovery process. In addition, it shows

\footnotetext{
1 Taylor (1988) and Vidyamurthy (2004) in the PPP and pairs trading literature respectively consider a cointegrating vector different from $(1,-1)$. However their approach is statistically rather than economically founded.
}

that the weights of the linear combination defining price discovery in the PT metric correspond to the price discovery parameters proposed by GS. Section 3 discusses the theoretical econometric background of the two techniques available to measure price discovery, the Hasbrouck's IS and the PT of Gonzalo-Granger. Section 4 presents empirical estimates of the model developed in Section $\mathbf{2}$ for five LME traded metals, it tests for cointegration and the presence of long run backwardation $\left(\beta_{2}>1\right)$, and estimates the contribution of the spot and futures prices to price discovery, testing the hypothesis of the futures price being the sole contributor to price discovery. A by-product of this empirical section is the computation of the unobserved convenience yields for all commodities. Section 5 concludes. Graphs are collected in the Appendix.

\section{Theoretical framework a model for price discovery in futures and spot markets}

The goal of this section is to characterize the dynamics of spot and futures commodity prices in an equilibrium no-arbitrage model, with finite elasticity of arbitrage services and existence of endogenous convenience yields. Our analysis builds and extends on GS setting up a perfect link with the Gonzalo-Granger PT decomposition. Following GS and for explanatory purposes we distinguish between two cases: (i) infinite and (ii) finite elastic supply of arbitrage services.

\subsection{Equilibrium prices with infinitely elastic supply of arbitrage services}

Let $S_{t}$ be the spot market price of a commodity in period $t$ and $s_{t}$ be its natural logarithm. Let $F_{\mathrm{r}}$ be the contemporaneous price of a futures contract for that commodity after a time interval $T-t>0$, and $f_{t}$ be its natural logarithm. In order to find the no-arbitrage equilibrium condition the following set of standard assumptions apply in this section:

- (a.1) No taxes or transaction costs.

- (a.2) No limitations on borrowing

- (a.3) No cost other than financing a (short or long) futures position and storage costs.

- (a.4) No limitations on short sale of the commodity in the spot market

- (a.5) Interest rates are determined by the process $r_{t}=\bar{r}+I(0)$ where $\bar{r}$ is the mean of $r_{t}$ and $I(0)$ is an stationary process with mean zero and finite positive variance.

- (a.6) Storage costs are determined by the process $c_{t}=\bar{c}+I(0)$ where $\bar{c}$ is the mean of $c_{t}$.

- (a.7) The difference $\Delta s_{t}=s_{t}-s_{t-1}$ is $I(0)$.

If $r_{t}$ and $c_{t}$ are the continuously compounded interest rates and storage costs applicable to the interval from $t$ to $T$, by the above assumptions (a.1)-(a.4), no-arbitrage equilibrium conditions imply

$F_{\mathrm{t}}=S_{\mathrm{t}} \mathrm{e}^{\left(\mathrm{r}_{\mathrm{t}}+\mathrm{c}_{\mathrm{t}}\right)(T-t)}$

Taking logs of expression (1), and considering $T-t=1$,

$f_{t}=s_{t}+r_{t}+c_{t}$. 
By (a.5) and (a.6), expression (2) can be rewritten as

$f_{\mathrm{t}}=\mathrm{s}_{\mathrm{t}}+\overline{\mathrm{rC}}+I(0)$

where $\overline{\mathrm{Ic}}=\overline{\mathrm{c}}+\overline{\mathrm{r}}$. From (a.7), Eq. (3) implies that $s_{\mathrm{t}}$ and $f_{\mathrm{t}}$ are cointegrated with the standard cointegrating relation $(1,-1) .^{2}$ This constitutes the standard case in the literature.

\subsection{Equilibrium prices with finitely elostic supply of arbitrage services} under the presence of convenience yield

There are a number of cases in which the elasticity of arbitrage services is not infinite in the real world. Factors such as the existence of basis risk, convenience yields, constraints on warehouse space, and the short run availability of capital, may restrict the supply of arbitrage services by making arbitrage transactions risky. From all these factors, in this paper we focus on the existence of convenience yields by explicitly incorporating them into the model. Users of consumption commodities may feel that ownership of the physical commodity provides benefits that are not obtained by holders of futures contracts. This makes them reluctant to sell the commodity and buy futures contracts resulting in positive convenience yields and price backwardations. There is a large amount of literature showing that commodity prices are often backwarded $\left(S_{t}>F_{t}\right)$. For example Litzenberger and Rabinowitz (1995) document that nine-month future prices are below the one-month prices $77 \%$ of the time for crude oil.

Convenience yield as defined by Brennan and Schwartz (1985) is "the flow of services that accrues to an owner of the physical commodity but not to an owner of a contract for future delivery of the commodity". Accordingly, backwardation is equal to the present value of the marginal convenience yield of the commodity inventory. A futures price that does not exceed the spot price by enough to cover "carrying cost" (interest plus warehousing cost) implies that storers get some other return from inventory. For example, a convenience yield can arise when holding inventory of an input lowers unit output cost and replacing inventory involves lumpy cost. Alternatively, time delays, lumpy replenishment cost, or high cost of short term changes in output can lead to a convenience yield on inventory held to meet customer demand for spot delivery.

Convenience yield is a concept from the theory of storage introduced by Kaldor (1939). Although our paper is not a study on storage or inventory theory, it acknowledges the existence of convenience yields and proposes a simple modelling that: (i) is consistent with the different approaches in the literature, (ii) helps to explain the empirical finding of a cointegrating vector different from $(1,-1)$, and (iii) is computationally simple. In general convenience yields are characterized or approximated by

$y_{t}=\mathbf{g}\left(s_{t}, f_{t}, X_{t}\right)$,

with $X_{t}$ a vector containing different variables such as interest rates, storage costs, and past convenience yields. The $g$ function satisfies $g_{1}=\delta y_{t} / \delta s_{t}>0$ and $g_{2}=\delta y_{t} / \delta f_{t}<0$. This function can be linear, as in Routledge et al. (2000) where $y_{t}$ is modelled as a linear function of storage costs, interest rates, spot prices and futures prices, or in Gibson and Schwartz (1990) where it is an autoregressive process with errors correlated with spot prices (see also Cassaus and Collin-Dufresne, 2005). It may also be nonlinear as in Heaney (2002), where the value of convenience yields is estimated using a trading strategy with options, and depends

\footnotetext{
2 Brenner and Kroner (1995) consider $r_{t}$ to be an I(1)process (random walk plus transitory component) and therefore they argue against cointegration between $s_{t}$ and $f_{t}$. Under this assumption $r_{t}$ should be explicitly incorporated into the long-run relationship between $s_{t}$ and $f_{t}$ in order to get a cointegrating relationship.
}

on the volatility of the spot and futures prices, plus the time to maturity of the futures contract. Independently of the framework applied, convenience yields have to satisfy the modified noarbitrage condition

$f_{t}+y_{t}=s_{t}+r_{t}+c_{t}$.

In this paper we approximate (4) by a linear combination of $s_{t}$ and $f_{t}$

$y_{t}=\gamma_{1} s_{t}-\gamma_{2} f_{t}, \quad \gamma_{i} \in(0,1), i=1,2$,

such that (5) holds.

Substituting (6) into (5) and taking into account (a.5)-(a.7) the following long run equilibrium is obtained

$s_{t}=\beta_{2} f_{t}+\beta_{3}+I(0)$,

with a cointegrating vector $\left(1,-\beta_{2},-\beta_{3}\right)$ where

$\beta_{2}=\frac{1-\gamma_{2}}{1-\gamma_{1}}$ and $\beta_{3}=\frac{-\overline{r c}}{1-\gamma_{1}}$.

It is important to notice the different values that $\beta_{2}$ can take and the consequences in each case:

(1) $\beta_{2}>1$ if and only if $\gamma_{1}>\gamma_{2}$. In this case we are under long run backwardation ( $s_{t}>f_{t}$ in the long run). ${ }^{3}$

(2) $\beta_{2}=1$ if an only if $\gamma_{1}=\gamma_{2}$. In this case we do not observe either backwardation or contango in the long run.

(3) $\beta_{2}<1$ if and only if $\gamma_{1}<\gamma_{2}$. In this case we are under long run contango ( $s_{t}<f_{t}$ in the long run).

In addition, the following remarks must be highlighted:

(a) The parameters $\gamma_{1}$ and $\gamma_{2}$ are identified from the equilibrium Eq. (7) once $\overline{r c}$ is known. Assigning a range of plausible values to this term, it is straightforward from (8) to obtain a sequence of $\gamma_{1}$ and $\gamma_{2}$, and therefore calculate convenience yields following (6). This is done in the empirical Section 4.4.1 for values of $\overline{r c}$ that range from $2 \%$ to $14 \%$ (15-month rate plus warehousing cost) and plotted in Figs. 6-10.

(b) Convenience yields are stationary when $\beta_{2}=1$. When $\beta_{2} \neq 1$ it contains a small random walk component ${ }^{4}$ Its size depends on the difference $\left(\beta_{2}-1\right)$ and it will thus be very small.

(c) Backwardation (contango) is on average associated with positive (negative) convenience yields.

To the best of our knowledge, this is the first instance in which the theoretical possibility of having a cointegrating vector different from $(1,-1)$ for a pair of $\log$ variables is formally considered in this literature. The finding of non unit cointegrating vector has been interpreted empirically in terms of a failure of the unbiasedness hypothesis (see for example Brenner and Kroner, 1995). However, it has never been modelled in a theoretical framework that allows for endogenous convenience yields and backwardation relationships.

To describe the interaction between cash and futures prices we must first specify the behavior of agents in the marketplace. Following GS, there are $N_{S}$ participants in the spot market and $N_{F}$ participants in futures market. Let $E_{i, t}$ be the endowment of the ith

\footnotetext{
3 For this statement $\bar{\pi}=0$ is assumed.

4 Convenience yields are equivalent to dividend yields for stock futures. If we accept this view, we can state that it is not the first time that convenience yields are considered to be I(1). For instance, Campbell and Yogo (2006) model dividend yields as a near-unit root or unit root process.
} 
participant immediately prior to period $t$ and $R_{i, t}$ the reservation price at which that participant is willing to hold the endowment $E_{i, t}$. Then the demand schedule of the ith participant in the cash market in period $t$ is

$E_{t, \mathrm{t}}-A\left(\mathrm{~s}_{\mathrm{t}}-R_{\mathrm{d}, \mathrm{t}}\right), \quad A>0, i=1, \ldots, N_{\mathrm{S}}$,

where $A$ is the elasticity of demand, assumed to be the same for all participants. Note that due to the dynamic structure imposed to the reservation price $R_{i, t}$, the relevant results in our theoretical framework are robust to a more general structure of the elasticity of demand, such as $A_{i}=A+a_{i}$, where $a_{i}$ is an independent random variable, with $E\left(a_{i}\right)=0$ and $V\left(a_{i}\right)=\sigma_{i}^{2}<\infty$.

The aggregate cash market demand schedule of arbitrageurs in period $t$ is

$H\left(\left(\beta_{2} f_{t}+\beta_{3}\right)-s_{t}\right), \quad H>0$,

where $H$ is the elasticity of spot market demand by arbitrageurs. As previously discussed, it is finite when the arbitrage transactions of buying in the spot market and selling in the futures market or vice versa are not risk free.

The cash market will clear at the value of $s_{t}$ that solves

$\sum_{i=1}^{N_{5}} E_{i, t}=\sum_{i=1}^{N_{5}}\left[E_{i, t}-A\left(s_{t}-R_{i, t}\right)\right]+H\left(\left(\beta_{2} f_{t}+\beta_{3}\right)-s_{t}\right)$.

The futures market will clear at the value of $f_{t}$ such that

$\sum_{j=1}^{N_{F}} E_{j, t}=\sum_{j=1}^{N_{F}}\left\{E_{j, t}-A\left(f_{t}-R_{J_{j} t}\right)\right\}+H\left(\left(\beta_{2} f_{t}+\beta_{3}\right)-s_{t}\right)$.

Solving Eqs. (11) and (12) for $f_{t}$ and $s_{t}$ as a function of the mean reservation price of spot market participants $\left(R_{t}^{S}=N_{S}^{-1} \sum_{f=1}^{N_{s}} R_{i, t}\right)$ and the mean reservation price for futures market participants $\left(R_{t}^{F}=N_{F}^{-1} \sum_{j=1}^{N_{F}} R_{j, t}\right)$, we obtain

$s_{\mathrm{t}}=\frac{\left(A N_{F}+H \beta_{2}\right) N_{S} R_{\mathrm{t}}^{S}+H N_{F} \beta_{2} R_{\mathrm{t}}^{F}+H N_{F} \beta_{3}}{\left(H+A N_{S}\right) N_{F}+H N_{S} \beta_{2}}$,

$f_{t}=\frac{H N_{S} R_{t}^{S}+\left(H+A N_{S}\right) N_{F} R_{t}^{F}-H N_{S} \beta_{3}}{\left(H+A N_{S}\right) N_{F}+H N_{S} \beta_{2}}$.

To derive the dynamic price relationships, the model in Eq. (13) must be characterized with a description of the evolution of reservation prices. It is assumed that immediately after market clearing in period $t-1$, the ith spot market participant was willing to hold amount $E_{t, t}$ at a price $s_{t-1}$. Following GS, this implies that $s_{t-1}$ was his reservation price after that clearing. We assume that this reservation price changes to $R_{i, t}$ according to the equation

$R_{i, t}=s_{t-1}+v_{t}+w_{i, t}, \quad i=1, \ldots, N_{S}$,

$R_{j, t}=f_{t-1}+v_{t}+w_{j, t}, \quad j=1, \ldots, N_{F}$,

$\operatorname{cov}\left(v_{t}, w_{i, t}\right)=0, \quad \forall_{i}$,

$\operatorname{cov}\left(w_{i, t}, w_{e, t}\right)=0, \quad \forall i \neq e$,

where the vector $\left(v_{t}, w_{l, t}, w_{j, t}\right)$ is vector white noise with finite variance.

The price change $R_{i, t}-s_{t-1}$ reflects the arrival of new information between period $t-1$ and period $t$ which changes the price at which the $i$ th participant is willing to hold the quantity $E_{i, t}$ of the commodity. This price change has a component common to all participants $\left(v_{t}\right)$ and a component idiosyncratic to the ith participant $\left(w_{i, t}\right)$. The equations in (14) imply that the mean reservation price in each market in period $t$ will be

$R_{t}^{S}=s_{t-1}+v_{t}+w_{t}^{F}, \quad i=1, \ldots, N_{S}$,

$R_{t}^{k}=f_{t-1}+v_{t}+w_{t}^{s}, \quad j=1, \ldots, N_{F}$, where, $w_{t}^{S}=\frac{\sum_{l=1}^{N_{5}} w_{j, t}^{S}}{N_{5}}, w_{t}^{F}=\frac{\sum_{j=1}^{N_{F}} w_{j, t}^{F}}{N_{F}}$. Substituting expressions (15) into (13) yields the following vector model

$$
\left(\begin{array}{l}
s_{t} \\
f_{t}
\end{array}\right)=\frac{H \beta_{3}}{d}\left(\begin{array}{c}
N_{F} \\
-N_{S}
\end{array}\right)+(M)\left(\begin{array}{l}
s_{t-1} \\
f_{t-1}
\end{array}\right)+\left(\begin{array}{l}
u_{t}^{s} \\
u_{t}^{F}
\end{array}\right),
$$

where

$\left(\begin{array}{l}u_{t}^{S} \\ u_{t}^{F}\end{array}\right)=(M)\left(\begin{array}{l}v_{t}+w_{t}^{S} \\ v_{t}+w_{t}^{F}\end{array}\right)$

$M=\frac{1}{d}\left(\begin{array}{cc}N_{S}\left(\beta_{2} H+A N_{F}\right) & \beta_{2} H N_{F} \\ H N_{S} & \left(H+A N_{S}\right) N_{F}\end{array}\right)$,

and

$d=\left(H+A N_{S}\right) N_{F}+\beta_{2} H N_{S}$.

GS perform their analysis of price discovery in an expression equivalent to (16). When $\beta_{2}=1_{*}$ GS conclude that the price discovery function depends on the number of participants in each market. In particular from (16) they propose the ratio

$\frac{N_{F}}{N_{S}+N_{F}}$,

as a measure of the importance of the futures market relative to the spot market in the price discovery process. Price discovery is therefore a function of the size of a market. Our analysis is taken further. Model (16) is converted into a Vector Error Correction Model (VECM) by subtracting $\left(s_{t-1}, f_{t-1}\right)^{\prime}$ from both sides,

$\left(\begin{array}{c}\Delta s_{t} \\ \Delta f_{t}\end{array}\right)=\frac{H \beta_{3}}{d}\left(\begin{array}{c}N_{F} \\ -N_{S}\end{array}\right)+(M-I)\left(\begin{array}{c}s_{t-1} \\ f_{t-1}\end{array}\right)+\left(\begin{array}{c}u_{t}^{s} \\ u_{t}^{F}\end{array}\right)$

with

$M-I=\frac{1}{d}\left(\begin{array}{cc}-H N_{F} & H N_{F} \beta_{2} \\ H N_{S} & -H N_{S} \beta_{2}\end{array}\right)$.

Rearranging terms,

$$
\left(\begin{array}{l}
\Delta s_{t} \\
\Delta f_{t}
\end{array}\right)=\frac{H}{d}\left(\begin{array}{c}
-N_{F} \\
N_{S}
\end{array}\right)\left(\begin{array}{lll}
1, & -\beta_{2}, & -\beta_{3}
\end{array}\right)\left(\begin{array}{l}
s_{t-1} \\
f_{t-1} \\
1
\end{array}\right)+\left(\begin{array}{l}
u_{t}^{s} \\
u_{t}^{F}
\end{array}\right) .
$$

In order to fully understand VECM (21) or (23) two interesting issues are worthwhile noting: (i) The evolution of the reservation prices described by (14) generates a unit root in both prices, and (ii) the (cash and futures) market clearing conditions (11) and (12) produce the reduced rank condition of the matrix $M-I$.

Applying the PT decomposition (described in Section 3) to this VECM, the permanent component will be the linear combination of $s_{t}$ and $f_{t}$ formed by the orthogonal vector (properly scaled) of the adjustment matrix $\left(-N_{F}, N_{s}\right)$. In other words the permanent component is

$\frac{N_{S}}{N_{S}+N_{F}} s_{t}+\frac{N_{F}}{N_{S}+N_{F}} f_{i}$.

This is our price discovery metric. The weights describing the permanent component correspond exactly to the contribution of each market to the price discovery process defined by GS. Note that our measure depends neither on $\beta_{2}$ (and thus on the existence of backwardation or contango) nor on the finite value of the elasticities $A$ and $H(>0)$. These elasticities do not affect the longrun equilibrium relationship, only the adjustment process and the error structure. For modelling purposes, it is important to notice that the long run equilibrium is determined by expressions (5) and (6), and it is the rest of the VECM (adjustment processes and error 
structure) that is affected by the different market assumptions on elasticities, participants, etc.

Two extreme cases with respect to $H$ are worthwhile discussing (at least mathematically):

(i) $H=0$. In this case there is no cointegration and thus no VECM representation. Spot and futures prices will follow independent random walks, futures contracts will be poor substitutes of spot market positions and prices in one market will have no implications for prices in the other market. This eliminates both the risk transfer and the price discovery functions of futures markets.

(ii) $H=\infty$. It can be shown that in this case the matrix $M$ in expression (13) has reduced rank and is such that $\left(1,-\beta_{2}\right) M=$ 0 . Therefore the long run equilibrium relationship (7), $s_{\mathrm{t}}=$ $\beta_{2} f_{t}+\beta_{3}$, becomes an exact relationship. Futures contracts are, in this situation, perfect substitutes for spot market positions and prices will be "discovered" in both markets simultaneously. In a sense, it can be said that this model is not suitable for $H=\infty$ because it produces a VECM with an error term with non-full rank covariance matrix.

\section{Two different metrics for price discovery: the IS of Hasbrouck and the PT of Gonzalo and Granger}

Currently there are two popular common factor metrics that are used to investigate the mechanics of price discovery: the IS of Hasbrouck (1995) and the PT of Gonzalo and Granger (1995) (see Lehman, 2002 special issue in the Journal of Financial Markets). Both approaches start from the estimation of the following VECM

$\Delta X_{t}=\alpha \beta^{\prime} X_{t-1}+\sum_{i=1}^{k} \Gamma_{i} \Delta X_{t-i}+u_{t}$,

with $X_{t}=\left(s_{t}, f_{t}\right)^{\prime}$ and $u_{t}$ a vector white noise with $E\left(u_{t}\right)=0$, $\operatorname{Var}\left(u_{t}\right)=\Omega>0$. To keep the exposition simple, we do not introduce deterministic components in (25).

The IS measure is a calculation that attributes the source of variation in the random walk component to the innovations in the various markets. To do that, Hasbrouck transforms Eq. (25) into a vector moving average (VMA)

$\Delta X_{t}=\Psi(L) u_{t}$,

and its integrated form

$X_{t}=\Psi(1) \sum_{i=1}^{t} u_{i}+\Psi^{*}(L) u_{t}$

where

$\Psi(1)=\beta_{\perp}\left(\alpha_{\perp}^{\prime}\left(I-\sum_{i=1}^{k} \Gamma_{i}\right) \beta_{\perp}\right)^{-1} \alpha_{\perp}^{\prime}$,

with

$\alpha_{\perp}^{\prime} \alpha=0$

$\beta_{\perp}^{\prime} \beta=0$.

$\Psi(L)$ and $\Psi^{*}(L)$ are matrix polynomials in the lag operator $L$, and the impact matrix $\Psi(1)$ is the sum of the moving average coefficients. Price levels can be re-written as

$X_{t}=\beta_{\perp} \psi\left(\sum_{t=1}^{t} u_{i}\right)+\Psi^{*}(L) u_{t}$,

with

$\psi=\left(\alpha_{\perp}^{\prime}\left(I-\sum_{i=1}^{k} \Gamma_{i}\right) \beta_{\perp}\right)^{-1} \alpha_{\perp}^{\prime}$
The last step on the calculation of the IS consists of eliminating the contemporaneous correlation in $u_{t}$. This is achieved by constructing a new set of errors

$u_{t}=Q e_{t}$,

with $Q$ the lower triangular matrix such that $\Omega=Q Q^{\prime}$.

The market-share of the innovation variance attributable to $e_{f}$ is computed as

$I S_{j}=\frac{\left([\psi Q]_{j}\right)^{2}}{\psi \Omega \psi^{\prime}}, \quad j=1,2$,

where $[\psi Q]_{j}$ is the $j$ th element of the row matrix $\psi Q$. This measure is invariant to the value of $\beta_{2}$.

Some comments on the IS approach should be noted. First, its lack of uniqueness. There is no a unique way of eliminating the contemporaneous correlation of the error $u_{t}$ (there are many square roots of the covariance matrix $\Omega$ ). Even if the Cholesky square root is chosen, there are two possibilities that produce different information share results. Hasbrouck (1995) bounds this indeterminacy for a given market $j$ information share by calculating an upper bound (placing that market's price first in the VECM) and a lower bound (placing that market last). These bounds can be very far apart from each other (see Huang, 2002). For this reason, the IS approach is more suitable for high frequency data, where correlation tends to be smaller. Second, it depends on the fact that the cointegration rank is $p-1$, with $p$ being the number of variables. When this is not the case, $\psi$ has more than a single row, and it is therefore unclear how to proceed in (33). In this situation the IS measure will not be invariant to the chosen row of $\psi$. Third, the IS methodology presents difficulties for testing. As Hasbrouck (1995) comments, asymptotic standard errors for the information shares are not easy to calculate. It is always possible to use some bootstrap methods as in Sapp (2002) for testing single hypotheses (for instance $I S_{1}=0$ ); but it is unclear how to proceed for testing joint hypotheses on different IS (for example $I S_{1}=I S_{2}$ ).

Harris et al. (1997) and Harris et al. (2002) were first in using the PT measure of Gonzalo-Granger for price discovery purposes. This PT decomposition imposes the permanent component $W_{t}$ to be a linear combination of the original variables, $X_{t *}$. This makes $W_{t}$ observable, and at the same time implies that the transitory component is also a linear combination of $X_{t}$ (in fact the cointegrating relationship $Z_{t}=\boldsymbol{\beta}^{\prime} \boldsymbol{X}_{t}$ ). The linear combination assumption, together with the definition of a PT decomposition fully identify the permanent component as

$W_{t}=\alpha_{\perp}^{\prime} X_{t}$,

and the PT decomposition of $X_{t}$ becomes

$X_{\mathrm{r}}=A_{1} \alpha_{\perp}^{\prime} X_{t}+A_{2} \beta^{\prime} X_{t}$

where

$A_{1}=\beta_{\perp}\left(\alpha_{\perp}^{\prime} \beta_{\perp}\right)^{-1}$,

$A_{2}=\alpha\left(\beta^{\prime} \alpha\right)^{-1}$.

The common permanent component constitutes the dominant price or market in the long run. The information that does not affect $W_{t}$ will not have a permanent effect on $X_{t}$. It is in this sense that $W_{t}$ is considered in the literature, as the linear combination that determines the contribution of each market (spot and futures) to the price discovery process. For these purposes the PT approach may have some advantages over the IS approach. First, the linear combination defining $W_{t}$ is unique (up to a scalar multiplication) and it is easily estimated by Least Squares from the VECM. 
Secondly, hypothesis testing of a given market contribution to the price discovery is simple and follows a chi-square distribution. And third, the simple economic model developed in Section 2 provides a solid theoretical ground for the use of the PT permanent component as a measure of the importance of each price in the price discovery process. There are situations in which the IS and PT approaches provide the same or similar results. This is discussed by Baillie et al. (2002). A comparison of both approaches can also be found in Yan and Zivot (2007). There are two drawbacks of the PT decomposition that are worthwhile noting. First, in order for (4) to exist we need to guarantee the existence of the inverse matrices involved in (36) (see Proposition 3 in Gonzalo and Granger, 1995). And second, the permanent component $W_{t}$ may not be a random walk. It will be a random walk when the VECM (25) does not contain any lags of $\Delta X_{t}$ (for instance, when both prices are a random walk) or in general when $\alpha_{\perp}^{\prime} \Gamma_{i}=0(i=1, \ldots, k)$.

The "key" parameter in both approaches is the matrix $\alpha_{\perp}$. Linear hypotheses on $\alpha_{\perp}$ can be tested: (i) directly on $\alpha_{\perp}$ or (ii) by testing the corresponding mirror hypotheses on $\alpha$. A LR test for the latter approach is developed in Johansen (1991) and for the former in Gonzalo and Granger (1995). Our recommendation is to use the simplest approach, and this is case dependent. In a bivariate system $(p=2)$ the second approach via a LR or Wald test is always easier to implement than the first one. This is not the case for larger systems. For instance with $p=3$ and cointegration rank $r=2$, there are cases where the first approach becomes much simpler. This is because only one hypothesis needs to be tested, while following the second approach implies two different restrictions in two vectors. ${ }^{5}$

\section{Empirical price discovery in non-ferrous metal markets}

The data include daily observations from the LME on spot and 15 -month forward prices for $\mathrm{Al}, \mathrm{Cu}, \mathrm{Pb}, \mathrm{Ni}$, and $\mathrm{Zn}$. Prices are available from January 1989 to October 2006. The data source is Ecowin. Quotations are denominated in dollars and reflect spot ask settlement prices and 15-month forward ask prices. The LME is not only a forward market but also the centre for physical spot trade in metals. The LME data has the advantage that there are simultaneous spot and forward prices, for fixed forward maturities, every business day. We look at quoted forward prices with time to maturity fixed to 15 months. These are reference future prices for delivery in the third Wednesday available within fifteen months delivery. Figs. 1-5 in the Appendix, depict spot settlement ask prices, 15-month forward ask prices, and spot-15-month backwardation (defined as $S_{t}-F_{t}$ ) for the five metals considered. A common feature that the figures show is that the degree of backwardation is highly correlated with prices, suggesting that high demand periods lead to backwardation structures. The data is thus consistent with the work of Routledge et a.l. (2000) which shows that forward curves are upward sloping in low demand states and slope downward in high demand states.

Our empirical analysis is based on the corresponding VECM (25). Econometric details of the estimation and inference of (25) can be found in Johansen $(1991,1996)$ and Juselius (20015). The procedure to estimate $\alpha_{\perp}$ and to test hypotheses directly on it are in Gonzalo and Granger (1995). Results are presented in Tables 1-4,

\footnotetext{
5 In a trivariate system with two cointegration vectors, suppose we are interested on testing that the first variable does not contribute to the common permanent component while the other two have equal contribution: $H_{0} * \alpha_{\perp}=$ $(0,1,1)^{\prime}\left(\varphi_{(1 \times 1)}\right)$. This corresponds to $\alpha_{(3 \times 2)}=\left(\alpha_{1,}, \alpha_{2}\right)$ with $\alpha_{1}=(*, 0,0)^{\prime}$ and $a_{2}=(*, 1,-1)^{\prime}$. The second approach is clearly outside the standard framework of testing the same restriction on all $\alpha$ implying a more difficult problem even for estimation purposes.
}

Table 1

Trace cointegration rank test

\begin{tabular}{lrrrrr}
\hline Trace test & Al & \multicolumn{1}{c}{ Cu } & \multicolumn{1}{c}{ Ni } & \multicolumn{1}{c}{ Pb } & \multicolumn{1}{c}{$\mathrm{Zn}$} \\
\hline$r \leq 1 \mathrm{vs} r=2(95 \%$ c.v $=9.14)$ & 1.02 & 1.85 & 0.57 & 0.84 & 5.23 \\
$r=0 \mathrm{vs} r=2(95 \%$ c.v $=20.16)$ & 27.73 & $15.64^{*}$ & 42.48 & 43.59 & 23.51 \\
\hline
\end{tabular}

- Significant at the $20 \%$ significance level ( $80 \%$ c.v $=15.56$ ).

Table 2

Estimation of the VECM (25)

$$
\begin{aligned}
& \text { Aluminium (AI) }
\end{aligned}
$$

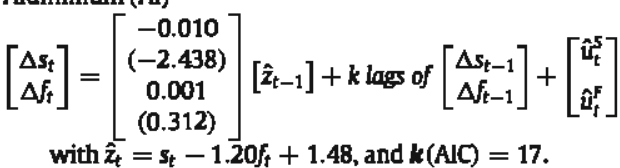

$$
\begin{aligned}
& \text { Copper (Cu) } \\
& {\left[\begin{array}{l}
\Delta s_{t} \\
\Delta f_{t}
\end{array}\right]=\left[\begin{array}{c}
-0.002 \\
(-0.871) \\
0.003 \\
(1.541)
\end{array}\right]\left[\hat{\mathbf{z}}_{t-1}\right]+k \log \text { of }\left[\begin{array}{l}
\Delta s_{t-1} \\
\Delta f_{t-1}
\end{array}\right]+\left[\begin{array}{l}
\hat{u}_{t}^{5} \\
\hat{u}_{t}^{F}
\end{array}\right]} \\
& \text { with } \hat{\mathbf{z}}_{t}=s_{t}-1.01 f_{t}+0.06 \text {, and } k(A) C=14 \text {. }
\end{aligned}
$$

$$
\begin{aligned}
& \text { Nickel (Ni) } \\
& {\left[\begin{array}{l}
\Delta s_{t} \\
\Delta f_{t}
\end{array}\right]=\left[\begin{array}{c}
-0.009 \\
(-2.211) \\
0.005 \\
(1.267)
\end{array}\right]\left[\hat{\underline{z}}_{t-1}\right]+k \text { lags of }\left[\begin{array}{l}
\Delta s_{t-1} \\
\Delta f_{t-1}
\end{array}\right]+\left[\begin{array}{c}
\hat{u}_{t}^{5} \\
\hat{u}_{t}^{F}
\end{array}\right]} \\
& \text { with } \hat{z}_{t}=s_{t}-1.19 f_{t}+1.69 \text {, and } k(A I C)=18 \text {. }
\end{aligned}
$$

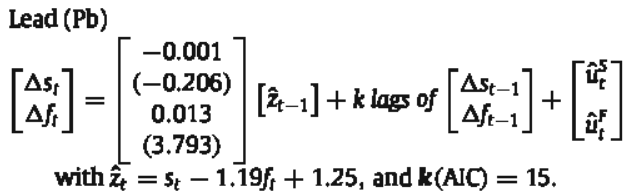

$$
\begin{aligned}
& \operatorname{Zinc}(\mathrm{Zn}) \\
& {\left[\begin{array}{l}
\Delta s_{t} \\
\Delta f_{t}
\end{array}\right]=\left[\begin{array}{c}
-0.009 \\
(-2.709) \\
0.001 \\
(0.319)
\end{array}\right]\left[\hat{\underline{x}}_{t-1}\right]+k \text { lags of }\left[\begin{array}{c}
\Delta s_{t-1} \\
\Delta f_{t-1}
\end{array}\right]+\left[\begin{array}{c}
\hat{u}_{t}^{s} \\
\hat{u}_{t}^{F}
\end{array}\right]} \\
& \text { with } \hat{z}_{t}=s_{t}-1.25 f_{t}+1.78 \text {, and } k(A I C)=16 \text {. }
\end{aligned}
$$

Note: $t$-statistics are given in parenthesis.

following the sequential number of steps corresponding to those that we propose for the empirical analysis and measuring of price discovery.

\subsection{Univariate unit root test}

Unit-root tests do not reject the null hypothesis of a unit root for any of the log prices. Results are available upon request.

\subsection{Determination of the rank of cointegration}

Before testing the rank of cointegration in the VECM specified in (25) two decisions are to be taken: (i) selecting the number of lags of $\left(\Delta s_{t}, \Delta f_{t}\right)^{\prime}$ necessary to obtain white noise errors, and (ii) deciding how to model the deterministic elements in the VECM. For the former, we use the information criterion, AIC, and for the latter we restrict the constant term to be inside the cointegrating relationship, as the economic model (23) suggests. Results on the Trace test are presented in Table 1. Critical values are taken from Juselius (2006). As it is predicted by our model, in all markets apart from copper, $s_{t}$ and $f_{t}$ are clearly cointegrated. In the case of copper, we fail to reject cointegration at the $80 \%$ confidence level. 


\subsection{Estimation of the VECM}

Results from estimating the reduced rank model specified in (25) are reported in Table $\mathbf{2}$ ( $t$-statistics are given in parenthesis). The following two characteristics are displayed: (i) all the cointegrating relationships tend to have a slope greater than one, suggesting that there is long-run backwardation. This is formally tested in step D; and (ii) with the exception of lead, in all estimated VECMs futures prices do not react significantly to the equilibrium error, whereas the spot price does. This suggests that futures prices are the main contributors to price discovery. We investigate this hypothesis in greater detail in step E.

Results reported in Table 2 may be used to construct the PT decomposition (35), see Figuerola-Ferretti and Gonzalo (2007) for further details.

\subsection{Hypothesis testing on beta}

Results reported in Table 3 show that the standard cointegrating vector $(1,-1)$ is rejected in all metal markets apart from copper, in favour of a cointegrating slope greater than one. This indicates that there is long run backwardation, implying that the size of backwardation has dominated the size of contango, and that if there were no more shocks into the system, in the long run the market would be in backwardation. This is not surprising since the extent of contango can be constrained by adding up inventory, to keep current spot prices from being too low relative to futures prices. However the extent of backwardation, which can be reduced by selling inventory, is unconstrained once stocks run down to zero.

One explanation for the surge of convenience yields in the metals industry may be found in Fama and French (1988). They show that metal production does not adjust quickly to positive demand shocks around business cycle peaks. As a consequence, inventories fall and forward prices are below spot prices. In response to their analysis, it may be argued that price backwardations and convenience yields arise due to the high costs of short term changes in output.

If we are prepared to accept cointegration in the copper market, our results suggest rejection of backwardation. We believe that there are two explanations for this. (i) The high use of recycling in the industry. Copper is a valuable metal and, like gold and silver it is rarely thrown away. In 1997, 37\% of copper consumption came from recycled copper. We contend that recycling provides a second source of supply in the industry and may be responsible for smoothing the convenience yield effect. (ii) Because of its frequent use for investment purposes, copper may behave like gold and silver in the sense that there are no restrictions on arbitrage arising from the existence of convenience yields. As it is the case for precious metals, this produces a cointegration vector of $(1,-1)$.

\subsubsection{Construction of convenience yields}

One of the advantages of our model is the possibility to calculate convenience yields. From expression (8),

$\gamma_{1}=1+\frac{\overline{r c}}{\beta_{3}}$ and $\gamma_{2}=1-\beta_{2}\left(1-\gamma_{1}\right)$,

given $\beta_{3} \neq 0$. The only unknown in (37) is $\overline{r c}$. This parameter is the average of the interest rates and storage costs. Non ferrous metal storage costs are provided by the LME (see www.Ime.com). These are usually very low and on the order of $1 \%$ to $2 \%$. In response to these figures, we have calculated convenience yields considering a range between $2.24 \%$ and $13.72 \%$. This is calculated taking maximum and minimum values of the 15 month interest rate, adding $1 \%$ to the minimum and $2 \%$ to the maximum. Given these values, the long-run convenience yield $y_{t}=\gamma_{1} s_{t}-$ $\gamma_{2} f_{\mathrm{t}}$ is computed, converted into annual rates, and plotted in Figs. $6-10 .{ }^{6}$ The only exception is copper because (37) can not be applied ( $\beta_{3}$ is not significantly different from zero). In this case the only useful information we have is that $\beta_{2}=1$, and therefore $\gamma_{1}=\gamma_{2}$. To calculate the corresponding range of convenience yields we have given values to these parameters that go from 0.85 to 0.99 . Fig. 7 plots the graphical result. Figs. 6-10 show two common features that are worth noting: (i) Convenience yields are positively related to backwardation price relationships, and (ii) convenience yields are remarkably high in times of excess demand leading to "stockouts", notably the 1989-1990 and the 2003-2006 sample sub-periods, both characterized by booming prices.

\subsection{Estimation of $\alpha_{\perp}$ and hypothesis testing}

Table 4 shows the contribution of spot and futures prices to the price discovery function. For all metals, with the exception of lead, futures prices are the determinant factor in the price discovery process. This conclusion is statistically obtained by the non-rejection of the null hypothesis $\alpha_{\perp}^{\prime}=(0,1)$. In the case of lead, the spot price is the determinant factor of price discovery (the hypothesis $\alpha_{\perp}^{\prime}=(1,0)$ is not rejected).

While for all commodities only one of the hypotheses $(0,1)$ or $(1,0)$ is not rejected, this is not the case for copper. In the copper market both the spot and futures prices contribute with equal weight to the price discovery process. As a result the hypothesis $\alpha_{\perp}^{\prime}=(1,1)$ cannot be rejected ( $p$-value $=0.79$ ). We are unable to offer a formal explanation for this result. We can only state that cointegration between spot and 15 -month prices is clearly weaker for copper and that this may be responsible for non rejection of the tested hypotheses on $\alpha_{\perp}$.

The finding that with the advent of centralized futures trading the preponderance of price discovery takes place in the futures market, is consistent with the literature on commodity price discovery, see Figuerola-Ferretti and Gilbert (2005) and references therein. In order to test whether such a finding is consistent with the model described in Section 2, we need to see whether the price discovery estimates reported in Table 4 are consistent with the relative number of players in each market. We therefore need to compare proxies for the number of participants in the spot and futures markets. A natural procedure would be to analyze volume information in the respective markets $\left(V_{S}\right.$ and $\left.V_{F}\right)$. In this way, $\alpha_{\perp}^{\prime}$ will become proportional to $\left(V_{S} /\left(V_{S}+V_{F}\right), V_{F} /\left(V_{S}+V_{F}\right)\right)$. Given the lack of spot volume data availability, we compare traded futures volumes as a share of World Refined Consumption (WRC). WRC reflects the value of volumes traded in the futures market, in the spot market, and in the option markets. This includes products traded in exchange and Over the Counter Markets (OTCs). Fig. 11 depicts average daily LME traded future volumes as share of WRC for the five metals considered for the 1994 to 2006 period. ${ }^{7}$

\footnotetext{
6 In response to those intervals we have calculated convenience yields for values of $\bar{\pi}=2 \%, 4 \%, 6 \%, 8 \%, 10 \%, 12 \%, 14 \%$.

7 Source for consumption data: World Bureau of Metal Statistics, World Metal Statistics (various issues). Source for volume data: LME and Ecowin LME contract size is 6 tons in nickel and 25 (equivalent to 55,115 lbs) for remaining contracts. The fact that the value of future volumes as share of WRC ranges between $8 \%$ and 12\% for the most important contracts indicates that a high percentage of trading takes place outside the exchange. This suggests that volume information based on LME volume figures, will only give a rough approximation regarding the number of participants in each market.
} 
Table 3

Hypothesis testing on the cointegrating vector and long run backwardation.

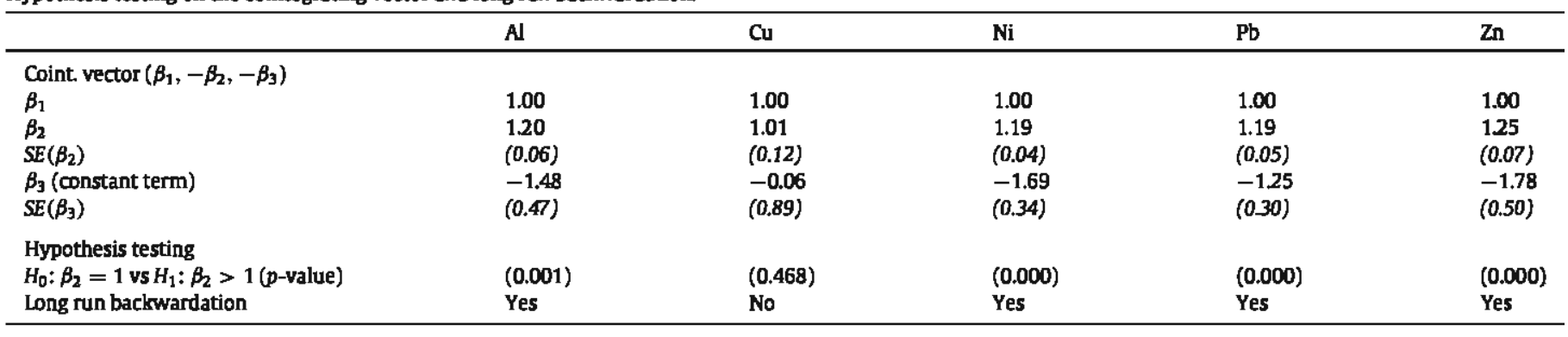

Table 4

Proportion of spot and future prices in the price discovery function ( $\left.\alpha_{\perp}\right)$

\begin{tabular}{|c|c|c|c|c|c|}
\hline Estimation & Al & $\mathrm{Cu}$ & $\mathbf{N i}$ & $\mathrm{Pb}$ & $\mathbf{Z n}$ \\
\hline $\begin{array}{l}\alpha_{1 \perp} \\
\alpha_{2 \perp}\end{array}$ & $\begin{array}{l}0.09 \\
0.91\end{array}$ & $\begin{array}{l}0.58 \\
0.42\end{array}$ & $\begin{array}{l}0.35 \\
0.65\end{array}$ & $\begin{array}{l}0.94 \\
0.06\end{array}$ & $\begin{array}{l}0.09 \\
0.91\end{array}$ \\
\hline $\begin{array}{l}\text { Hypothesis testin } \\
H_{0}: \alpha_{\perp}^{\prime}=(0,1) \\
H_{0}: \alpha_{\perp}^{\prime}=(1,0)\end{array}$ & $\begin{array}{l}(0.755) \\
(0.015)\end{array}$ & $\begin{array}{l}(0.123) \\
(0.384)\end{array}$ & $\begin{array}{l}(0.205) \\
(0.027)\end{array}$ & $\begin{array}{l}(0.000) \\
(0.837)\end{array}$ & $\begin{array}{l}(0.749) \\
(0.007)\end{array}$ \\
\hline
\end{tabular}

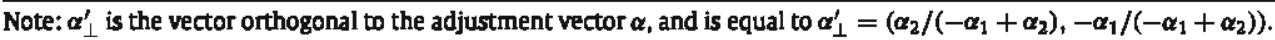

Two important remarks from Fig. 11: (i) The lead market has been the least important metal in terms of futures volumes traded. This is consistent with our result which suggests that lead is the least liquid LME traded futures contract. (ii) Copper appears as the most important metal in terms of future volumes traded as a share of WRC This is not fully consistent with the price discovery results reported in the paper, which suggest that neither the futures nor the spot market are the sole contributors to discovery. The main reason for this controversy lies behind the fact that copper spot and futures prices show very weak cointegration (only at the $80 \%$ confidence level). We are unable to explain this result We can only suggest that the model of Section 2.2 may not be fully applicable to copper which, as shown in Fig. 12, is also significantly traded in COMEX (the metal platform of NYMEX). Copper COMEX volumes, ${ }^{8}$ have reached a share over total volumes traded ( $\left.V_{\text {Ime }}+V_{\text {comex }}\right)$ of almost $16 \%$ in 2006. This implies that there is an additional market trading spot and futures copper contracts, and that quoted prices in this market also play a role in the price discovery process. A complete analysis of this fact and copper's other idiosyncratic issues (recycling, speculative behaviour, etc.) is under current research.

\section{Conclusions, implications and extensions}

The process of price discovery is crucial for all participants in commodity markets. The present paper models and measures this process by extending the work of CS to consider the existence of convenience yields in spot-future price equilibrium relationships. The proposed model of convenience yields with I(1) prices captures the presence of long-run backwardation or contango structures, which are reflected in the cointegrating vector $\left(1,-\beta_{2}\right)$ with $\beta_{2} \neq 1$. When $\beta_{2}>1(<1)$ the market is under longrun backwardation (contango). This is the first contribution of this paper. As a by-product, we find a theoretical justification for a cointegrating vector between log-variables different from the standard $(1,-1)$. To the best of our knowledge this is the first time in which non unit cointegration vectors are formally considered in this literature. Secondly, our model allows simple calculation of

\footnotetext{
8 Source for volume data is COMEX Contract size is $44,000 \mathrm{lbs}$ for aluminium and 25,000 for copper.
}

unobserved convenience yields. Thirdly, we show that, under very general conditions, including finite elasticity of supply of arbitrage, the model admits an economically meaningful Error Correction Representation. Under this framework, the linear combination of $s_{t}$ and $f_{t}$ characterizing the price discovery process coincides exactly with the permanent component of the Gonzalo-Granger PT decomposition. And fourthly, we propose an empirical strategy based on five simple steps to test for long-run backwardation, and estimate and test the importance of each price (spot and future) in the price discovery process.

Applied to LME spot and futures prices for five metals ( $\mathrm{Al}, \mathrm{Cu}$ $\mathrm{Ni}, \mathrm{Pb}, \mathrm{Zn}$ ), our technique suggests that, with the exception of $\mathrm{Cu}$, all markets are in long-run backwardation. More importantly, for those markets with highly liquid futures trading, the preponderance of price discovery takes place in the futures market.

Extensions to this paper include the use of the approach in Gonzalo and Pitarakis (2006) to consider different regimes reflecting backwardation (contango) structures and their impact into the VECM and PT decomposition. The flexible non linear VECM framework is crucial to allow for time variation in the number of participants in the spot and futures markets, an important consideration that has been left for future research.

\section{Acknowledgements}

We are grateful to two anonymous referees for insightful and constructive suggestions that have improved the paper. We also thank Christopher L. Gilbert, Seongman Moon, Alfonso Novales, Ioannis Paraskevopoulos, Sabine Schels, and seminar participants at the "20 Years of Cointegration" Conference (Rotterdam), Chinese Academy of Sciences, Instituto de Empresa, Universidad Carlos III de Madrid, Universidad Complutense, Universidad de Zaragoza, University of California-Riverside, University of Southampton, and University of St Andrews for helpful comments and suggestions. We are grateful to the Spanish Ministerio de Ciencia e Innovacion, grants SEJ2006-09401, SEJ2007-63098 and CONSOLIDER 2010 (CSD 2006-00016) and to DGUCM (Community of Madrid) grant EXCELECON S-2007/HUM-044 for partially supporting this research 


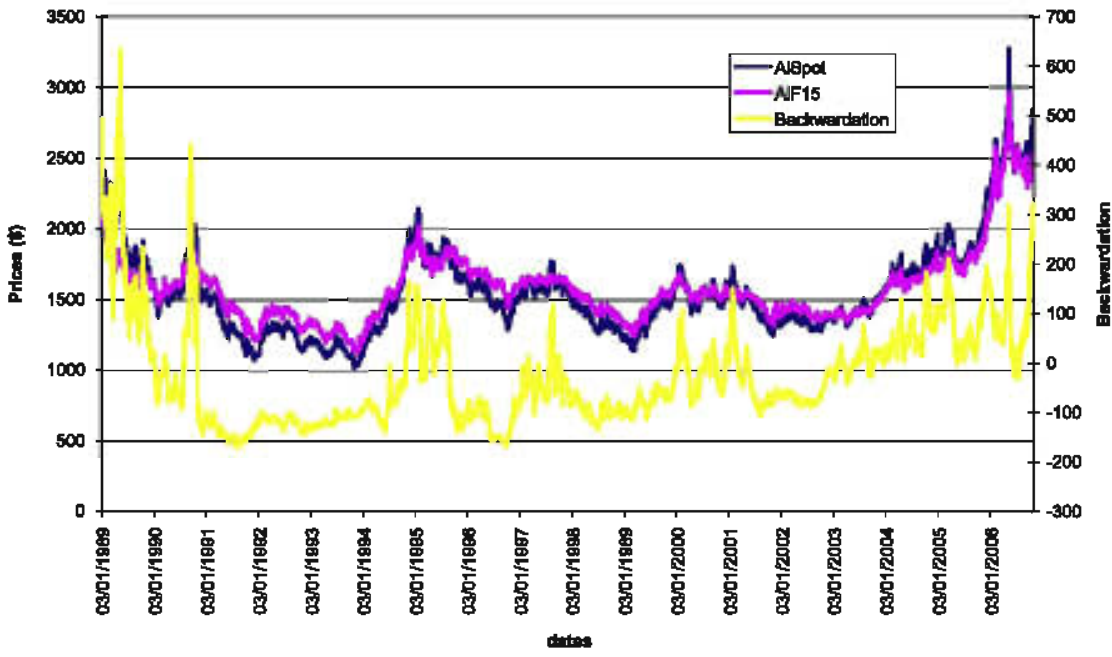

Fig 1. Daily aluminium spot ask settlement prices 15 -month forward ask prices, and backwardation $\left(S_{t}-F_{t}\right)$. January 1989-October 2006.

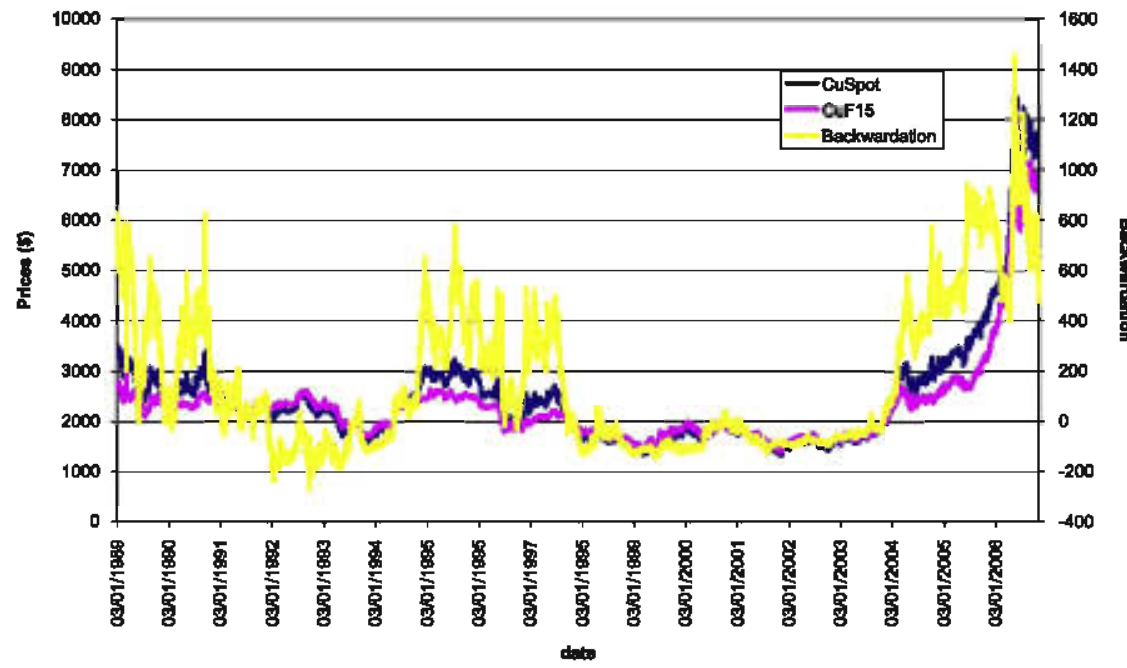

Fig 2. Daily copper spot ask settlement prices, 15 month forward ask prices and backwardation $\left(S_{t}-F_{t}\right)$. January $1989-O c t o b e r 2006$

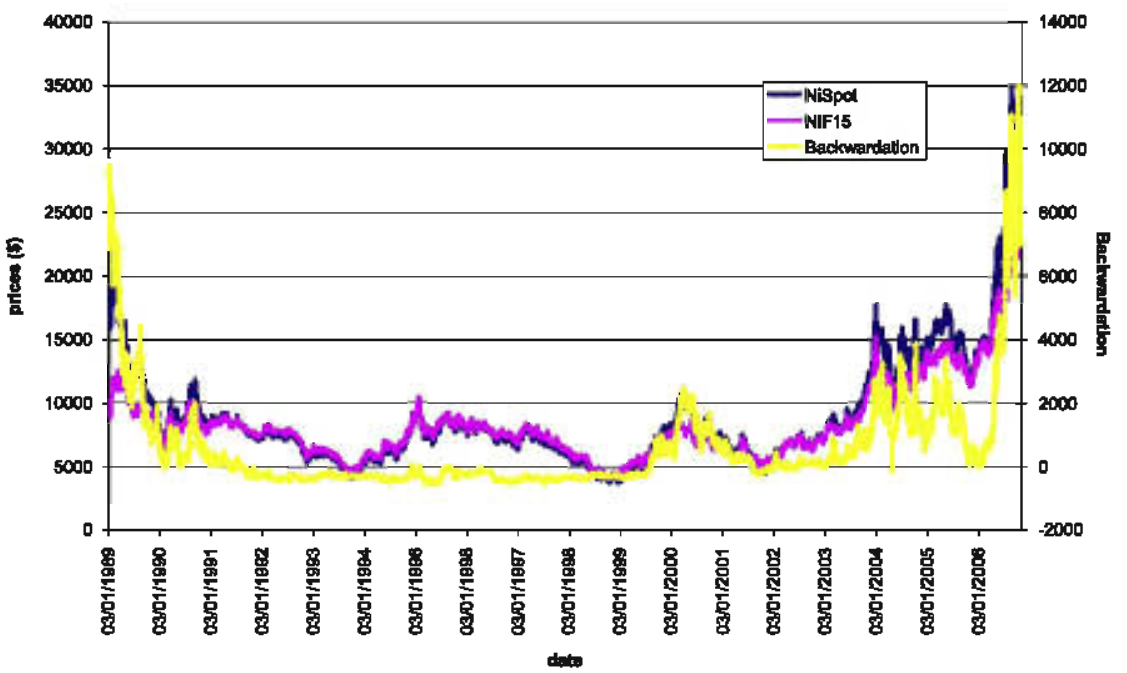

Fig 3. Daily nickel spot ask settlement prices, 15-month ask forward prices and backwardation ( $\left.S_{t}-F_{\mathrm{f}}\right)$. January 1989-0ctober 2006. 


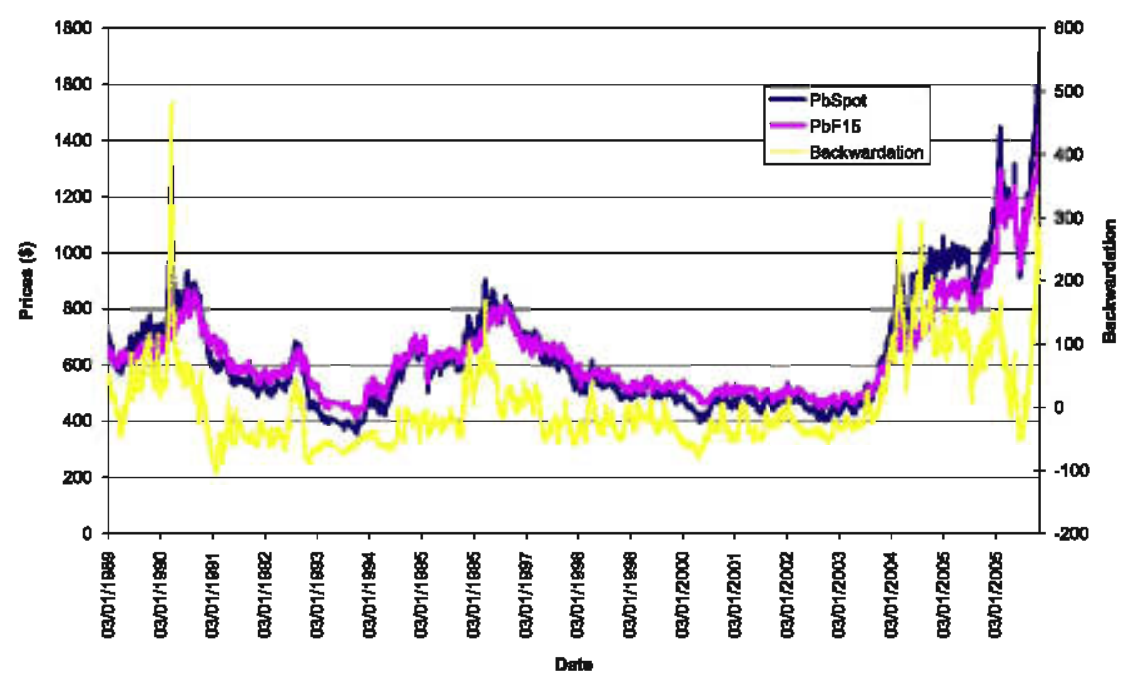

Fig 4. Daily lead spot settlement prices, 15-month forward prices and backwardation $\left(S_{t}-F_{t}\right)$. January 1989-0ctober 2006.

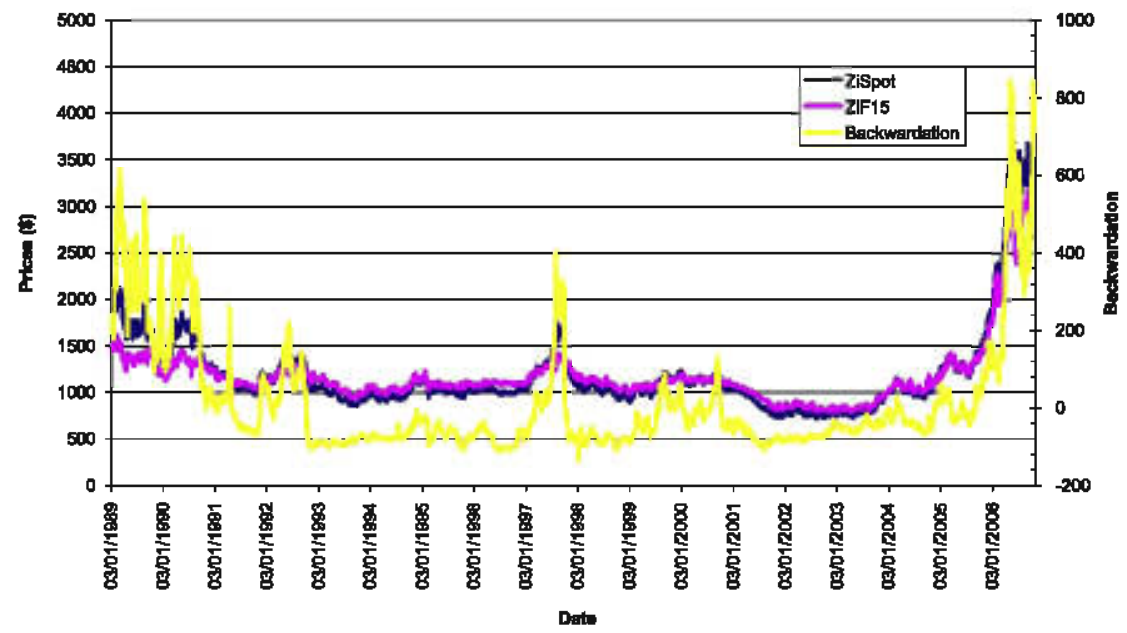

Fig. 5. Dạily zinc spot ask settlement prices, 15-month forward prices and backwạrdation $\left(S_{t}-F_{t}\right)$. January 1989-December 2006.

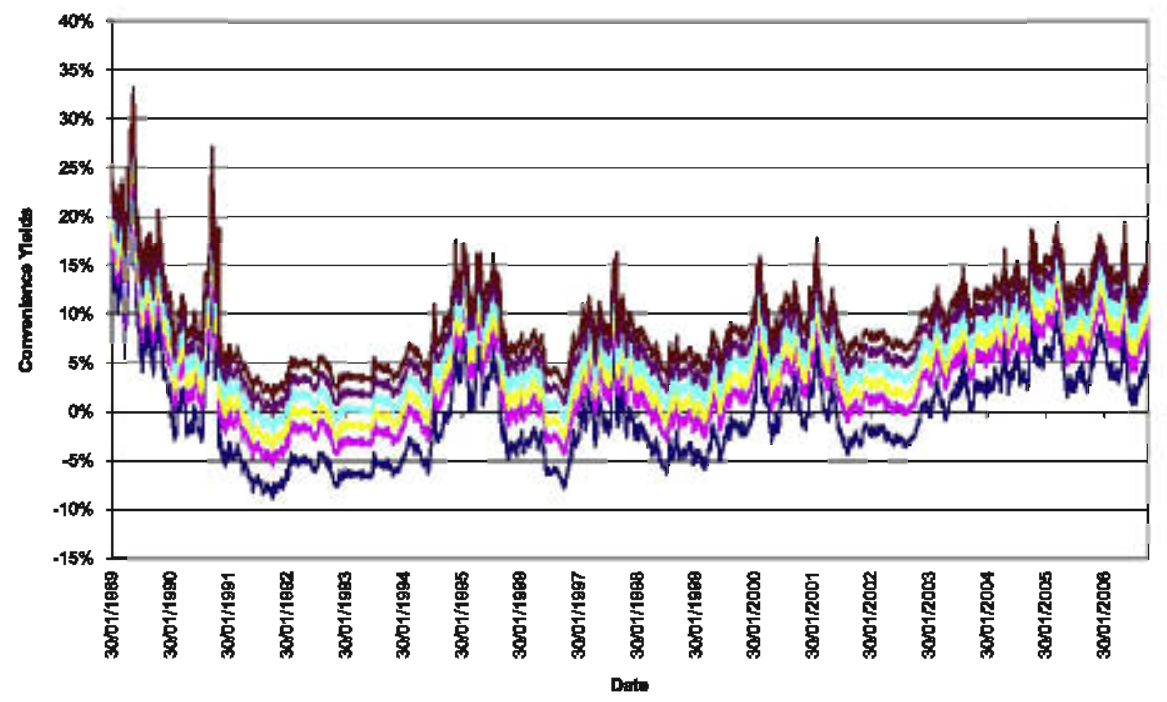

Note: Convenience Yields $y_{1}=\gamma_{1} s_{1}-\gamma_{2} f_{i} ; \gamma_{1}=1+\frac{\overline{\bar{C}}}{\beta_{3}} ; \gamma_{2}=1-\beta_{2}\left(1-\gamma_{1}\right) ; \overline{\pi c}=[2 \%, 14 \%]$

Flg 6. Aluminium annual convenience yields. 


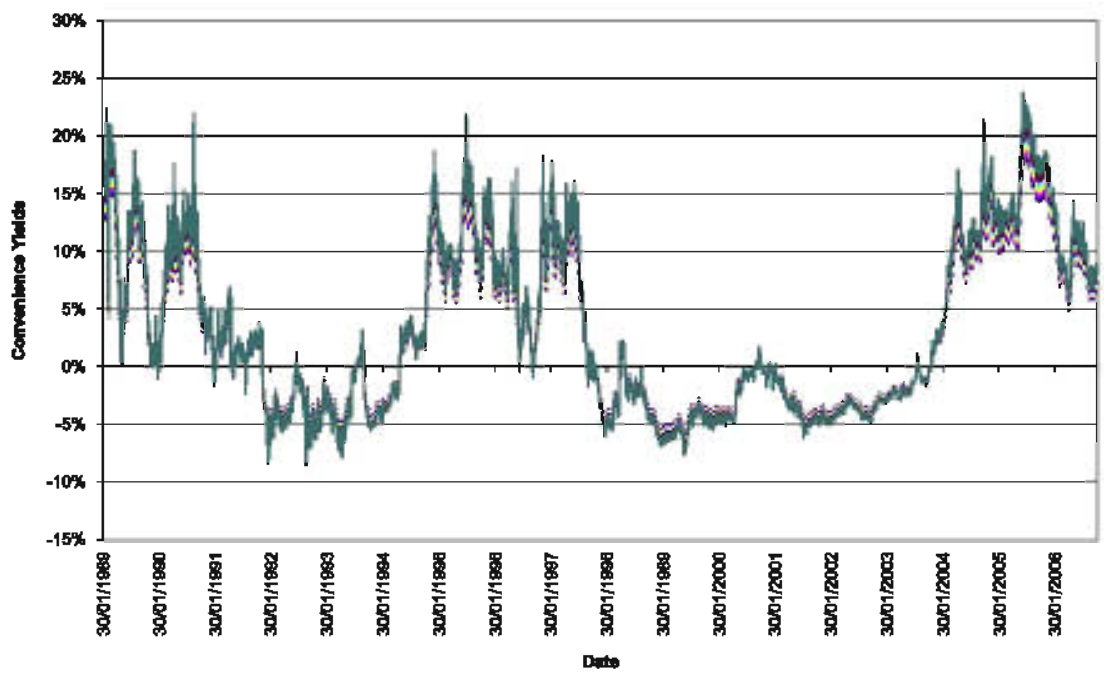

Note: Convenience Yields $y_{t}=y_{1} s_{t}-y_{2} f_{i} ; y_{1}=y_{2}=[0.85,0.99]$

Ftg 7. Copper annual convenience yields.

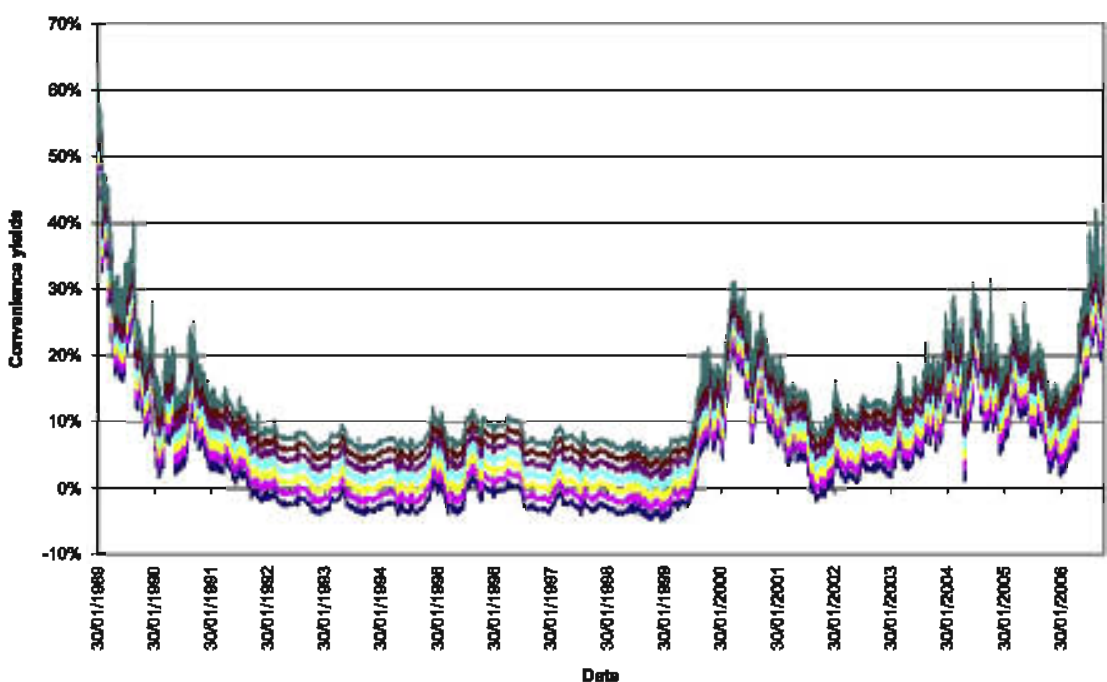

Note : Convenience Yields $y_{t}=\gamma_{1} s_{t}-\gamma_{2} f_{t} ; \gamma_{1}=1+\frac{\bar{\pi}}{\beta_{3}} ; \gamma_{2}=1-\beta_{2}\left(1-\gamma_{1}\right) ; \overline{\pi c}=[2 \%, 14 \%]$

Ftg 8. Nickel annual convenience yields.

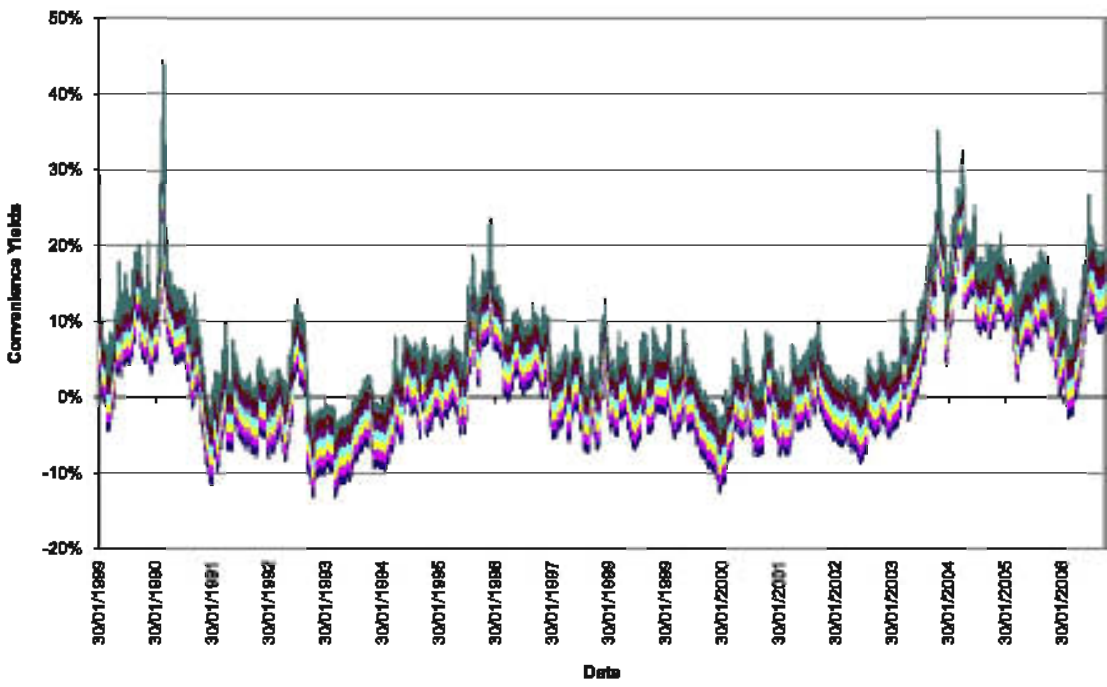

Note: Convenience Yields $y_{t}=\gamma_{1} s_{t}-\gamma_{2} f_{i} ; \gamma_{1}=1+\frac{\bar{c}}{\beta} ; \gamma_{2}=1-\beta_{2}\left(1-\gamma_{1}\right) ; \overline{\pi c}=[2 \%, 14 \%]$

Fig 9. Lead annual convenience yields. 


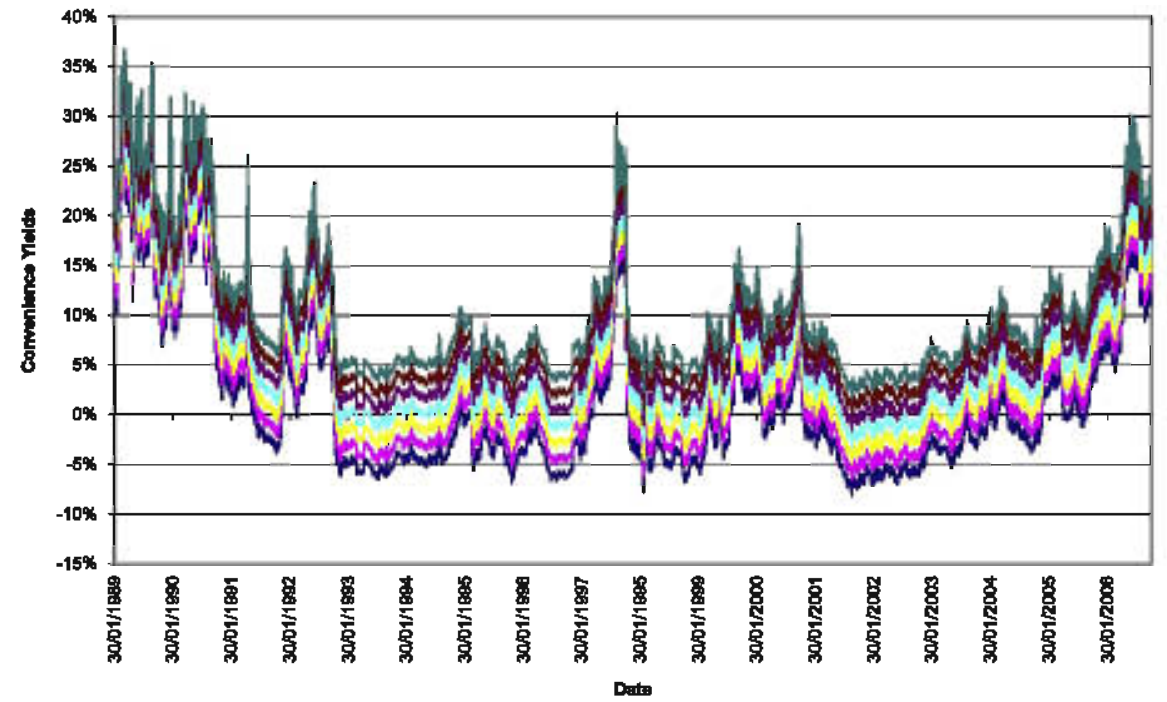

Note: Convenience Yields $y_{t}=\gamma_{1} s_{1}-\gamma_{2} f_{t} ; \gamma_{1}=1+\frac{\bar{\tau}}{\beta_{3}} ; \gamma_{2}=1-\beta_{2}\left(1-\gamma_{1}\right) ; \overline{\pi c}=[2 \%, 14 \%]$

Fig 10. Zinc annual convenience yields.

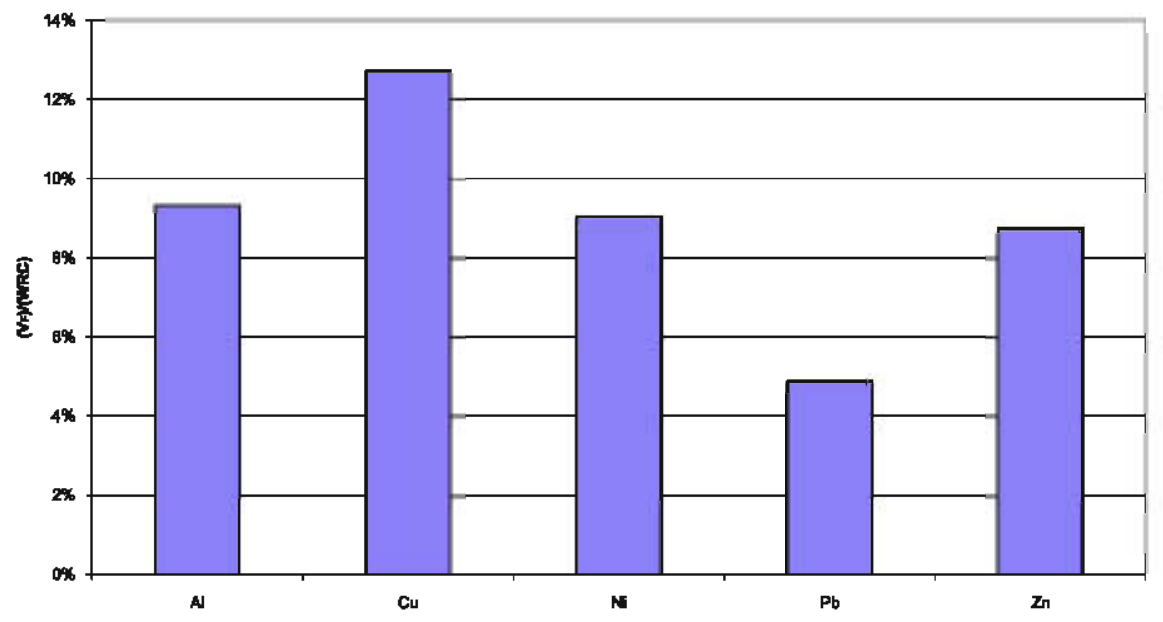

Flg 11. Average daily LME futures trading volume over world refined consumption. Non-ferrous metals. January 1994-October 2006.

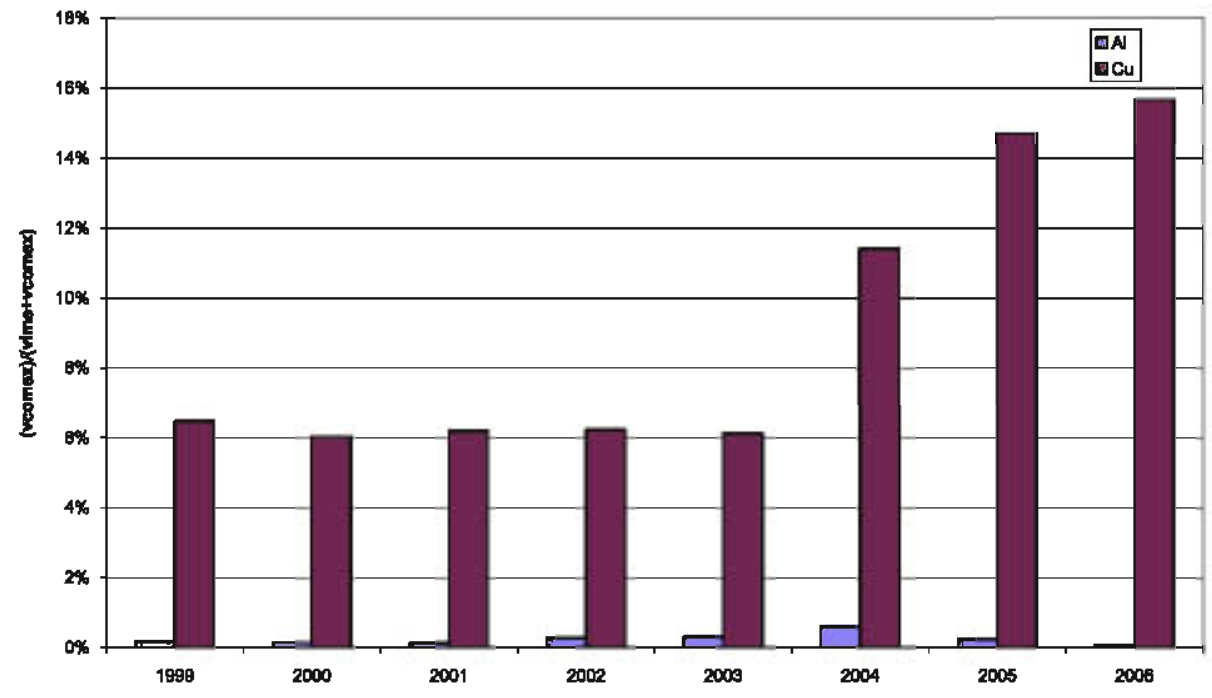

Flg 12. Daily COMEX copper and aluminium volumes traded. Jan 1999 to October 2006. 


\section{References}

Baillie, R, Goffrey, G., Tse, Y., Zabobina, T, 2002. Price discovery and common factor models. Journal of Financial Markets 5, 309-325.

Brennan, M.J., Schwartz, E., 1985. Evaluing natural resource investments. Journal of Business 58, 135-157.

Brenner, RJ., Kroner, K., 1995. Arbitrage, cointegration, and testing the unbiasedness hypothesis in financial markets. Journal of Finance and Quantitative Analysis 30 23-42.

Campbell, J., Yogo, M., 2006. Efficient tests of stock return predictability. Journal of Financial Economics 81, 27-60.

Cassaus, J., Collin-Dufresne, P., 2005. Stochastic convenience yield implied from commodity futures and interest rates. Journal of Finance 60, 2283-2331.

Engle, RF., Granger, CW.J., 1987. Cointegration and error correction: Representation, estimation, and testing. Econometrica 55, 251-276.

Fama, E., French, K.R., 1988. Business cycles and the behaviour of metals prices. Journal of Finance 43, 1075-1093.

Figuerola-Ferretti, I., Gilbert, C.L, 2005. Price discovery in the aluminium market. Journal of Futures Markets 25, 967-988.

Figuerola-Ferretti, I., Gonzalo, J., 2007. Modeling and measuring price discovery in commodity markets. Working Paper 07-45-11. Business Department, U. Carlos III de Madrid.

Gaウade, K.D., Silber, W.L, 1983. Price movements and price discovery in futures and cash markets. Review of Economics and Statistics 65, 289-297.

Gibson, R, Schwartz, E., 1990. Stochastic convenience yield and the pricing of oil contingent claims. Journal of Finance 45, 959-956.

Gonzalo, J., Granger, C.W.J., 1995. Estimation of common long-memory components in cointegrated systems. Journal of Business and Economic Statistics 13, 27-36.

Gonzalo, J., Pitarakis, J., 2006. Threshold effects in multivariate error correction models. In: Palgrave Handbook of Econometrics, vol. 1 (Chapter 15).

Harris, F.H., Mclnish, T.H., Wood, R.A. 1997. Common long-memory components of intraday stock prices: a measure of price discovery. Working Paper. Wake Forest University.

Harris, F.H., Mclnish, T.H., Wood, R.A, 2002. Security price adjustment across exchanges: an investigation of common factor components for Dow stocks. Journal of Financial Markets 5, 277-308.
Hasbrouck, J., 1995. One security, many markets: determining the contributions to price discovery. Journal of Finance 50, 1175-1199.

Heaney, R, 2002. Approximation of convenience yield for commodity futures markets. Journal of Futures Markets 22, 1005-1017.

Huang, RD., 2002. The Quality of ECN and Nasdaq market maker quotes. Journal of Finance 57, 1285-1319.

Johansen, S., 1991. Estimation and hypothesis testing of cointegration vectors in Gaussian autoregressive models. Econometrica 59, 1551-1580.

Johansen, S., 1996. Likelihood-based Inference in Cointegrated Vector Autoregressive Models, 2nd ed. Oxford University Press, Oxford.

Juselius, K., 2006. The Cointegrated VAR Model: Methodology and Applications. Oxford University Press, Oxford

Kaldor, N., 1939. Speculation and economic stability. Review of Economic Studies 7, 1-27.

Lehman, B.N., 2002. Journal of Financial Markets 5, 3 (special issue).

Lake, F., 1978. The Miller's Use of the commodity exchange. In: Peck, A. (Ed.), Views from the Trade. Board of Trade of the City of Chicago, Chicago.

Litzenberger, R, Rabinowitz, N., 1995. Backwardation in oil futures markets: theory and empirical evidence. Journal of Finance 50, 1517-1545.

Routledge, B.R, Seppi, DJ, Spatt, CS., 2000. Equilibrium forward curves for commodities. Journal of Finance 55, 1297-1337.

Sapp, S., 2002. Price leadership in the spot foreign exchange market Journal of Financial and Quantitative Analysis 37, 425-448.

Stein, J.L, 1961. The simultaneous determination of spot and future prices. Anerican Economic Review 51, 1012-1025.

Taylor, M., 1988. An empirical examination of long-run purchasing power parity using cointegration techniques. Applied Economics 20, 1369-1381.

Vidyamurthy, G., 2004. Pairs Trading, Quantitative Methods and Analysis. Jolin Wiley \& Sons, Canada.

Wiese, V., 1978. Use of commodity exchanges by local grain marketing organizations. In: Peck, A. (Ed.), Views from the Trade. Board of Trade of the City of Chicago, Chicago.

Working, H., 1948. Theory of the inverse carrying charge in futures markets. Journal of Farm Economics 30, 1-28.

Yan, B, Zivot, E, 2007. The dynamics of price discovery. Working Paper. Department of Economics, University of Washington. 